\title{
EFFECT OF SIZE ON FORCED CONVECTION GREENHOUSE DRYING OF KHOA
}

\author{
Mahesh Kumar \\ Faculty of Mechanical Engineering, \\ Guru Jambheshwar University of Science \& Technology, 125001, Hisar, India \\ Email: mkshandilya1@gmail.com \\ Phone: +911662263564; Fax: +911662276025
}

\begin{abstract}
Khoa, a heat desiccated milk product, forms an important base for preparation of milk sweets. In this communication, an attempt is made to evaluate the convective heat and mass transfer coefficients during forced convection greenhouse drying of different sizes of khoa samples. Experiments were conducted during the month of October 2012 at Guru Jambheshwar University of Science \& Technology Hisar. Khoa pieces of different dimensions with a total quantity of $100 \mathrm{~g}$ were dried in a roof type even span greenhouse with a floor area of $1.2 \times 0.8 \mathrm{~m}^{2}$ till almost no variation in its mass was recorded. Hourly data on the mass evaporated, temperature of khoa, relative humidity and temperature inside the greenhouse structure were recorded. These data were used to determine the values of convective heat transfer coefficients by regression analysis, and the convective mass transfer coefficients were consequently evaluated. The convective heat and mass transfer coefficients were observed to increase with the decrease in khoa sample size for the given size of greenhouse. The experimental error in terms of percent uncertainty was also evaluated, and observed to vary in the range of $14.99 \%$ to $23.24 \%$.
\end{abstract}

Keywords: Khoa; khoa drying; convective mass transfer coefficient; greenhouse drying; forced convection.

\section{INTRODUCTION}

India is the world's largest and fastest growing market for milk and milk products. Khoa, a traditional heat-desiccated, partially dehydrated milk product, is a rich source of energy (about $1914.4 \mathrm{~kJ}$ per $100 \mathrm{~g}$ of the product). It forms an important base for preparation of milk sweets which are an integral part of the Indian food heritage [1]. The total Indian sweet market is worth around 520 billion rupees in terms of annual sales [2]. In India, winter is the flush season for milk production because of the increased breeding of cattle, as well as the better availability of crop residues and agricultural by-products. So, in many places, khoa is manufactured on a large scale in the months of January to February. The shelf life of khoa is chiefly influenced by the moisture content, among other factors like storage temperature, raw material quality, sanitation conditions, and packaging $[1,2]$. The moisture content permits the growth of mould. The presence of mould in khoa causes its rapid deterioration by producing discoloration defects as well as disagreeable flavours within a few days of storage at room temperature [2]. 
Solar energy is an abundant, non-pollutant, freely available and renewable form of energy which can be effectively used for khoa drying, if it is harvested properly. Drying of khoa is basically a heat and mass transfer phenomenon. The heat from the surrounding air and the sun transfers to the khoa surface by different heat transfer mode. A part of this heat travels to the interior of the khoa and removes the moisture from the interior to its surface by heat transfer, taking the latent heat of vaporization. The remaining part of the heat is utilized to increase the khoa surface temperature, which causes evaporation of the moisture to the surrounding air in the form of sensible heat. Greenhouse drying is an advanced and alternative method to the traditional techniques. The product is placed in trays and receives solar radiation through the plastic cover, while moisture is removed by natural convection or forced air flow. This double function, greenhouse and dryer, improves the return rate of the initial investment. It helps in maintaining the quality, increases the storage period, and reduces wastage of the product $[3,4]$.

The convective heat transfer coefficient during khoa drying is the critical parameter required for proper design of dryers. It depends on the temperature difference between the khoa surface and air, and the thermal-physical properties of humid air surrounding the khoa. The convective mass transfer coefficients for various shapes and sizes of jaggery pieces in a controlled environment were evaluated [5]. It was observed that the heat transfer coefficient in forced convection is higher than the natural convection mode. The effects of shape and size of jaggery for a given mass on the convective mass transfer coefficient for natural as well as forced convection greenhouse drying were studied [6]. The convective heat transfer coefficients of khoa were investigated in open sun drying and greenhouse drying for natural as well as for forced convection modes for three consecutive days using a khoa piece sample of size $0.09 \times$ $0.06 \times 0.015 \mathrm{~m}^{3}$ [7]. The convective heat transfer coefficients in forced convection were higher than the natural convection mode and were reported to decrease with the drying day progression from the first day to the third day. The convective heat transfer coefficients were observed to vary in a range of 0.54 to $1.09 \mathrm{~W} / \mathrm{m}^{2}{ }^{\circ} \mathrm{C}$. Recently, the convective heat and mass transfer coefficient for khoa drying under natural convection greenhouse mode for different sizes of khoa samples for a given mass were evaluated [8]. The average values of convective heat and mass transfer coefficients were reported to increase from 1.59 to $2.53 \mathrm{~W} / \mathrm{m}^{2}{ }^{\circ} \mathrm{C}$ and 39.95 to $60.6 \mathrm{~W} / \mathrm{m}^{2}{ }^{\circ} \mathrm{C}$ respectively when decreasing the size of khoa pieces from $0.075 \times 0.06 \times 0.015 \mathrm{~m}^{3}$ to $0.025 \times 0.02 \times$ $0.015 \mathrm{~m}^{3}$. In the present research work, the effect of size on the convective heat and mass transfer coefficients of khoa for a given mass with greenhouse drying under forced convection mode has been evaluated. This study will be helpful in the design of a dryer for drying khoa to retain its quality for storage.

\section{MATERIALS AND METHODS}

\section{Experimental Set-up and Instrumentation}

A roof type even span greenhouse of $1.2 \times 0.8 \mathrm{~m}^{2}$ floor area was fabricated from PVC pipe and a UV film covering. The central height and the walls were maintained as 0.6 and $0.4 \mathrm{~m}$ respectively. For the forced convection mode, a fan of $225 \mathrm{~mm}$ sweep diameter and $1340 \mathrm{rpm}$ with a rated air velocity of $5 \mathrm{~m} / \mathrm{s}$ was fitted on the sidewall of the greenhouse. The schematic of the experimental set-up is illustrated in Figure 1. The 
experimental set-up was located on the open floor of a three-floor building and the orientation of the greenhouse was kept east-west during the experimentation. Khoa pieces of $1.5 \mathrm{~cm}$ thickness for single layer drying were kept in a wire mesh tray of 0.09 $\mathrm{m} \times 0.06 \mathrm{~m}$ size over the digital weighing balance of $6 \mathrm{~kg}$ capacity with a least count of $0.1 \mathrm{~g}$. The temperatures of khoa and air at different locations were measured by calibrated copper-constantan thermocouples connected to a 10-channel digital temperature indicator with a least count of $0.1{ }^{\circ} \mathrm{C}$. The thermocouples were calibrated with respect to the ZEAL thermometer. The relative humidity $(\gamma$ or $\mathrm{RH})$ and the temperature just above the khoa surface were measured by a digital humidity/temperature meter (model Lutron-HT 3006, Taiwan) with a least count of $0.1 \% \mathrm{RH}$ and $0.1{ }^{\circ} \mathrm{C}$ temperature.

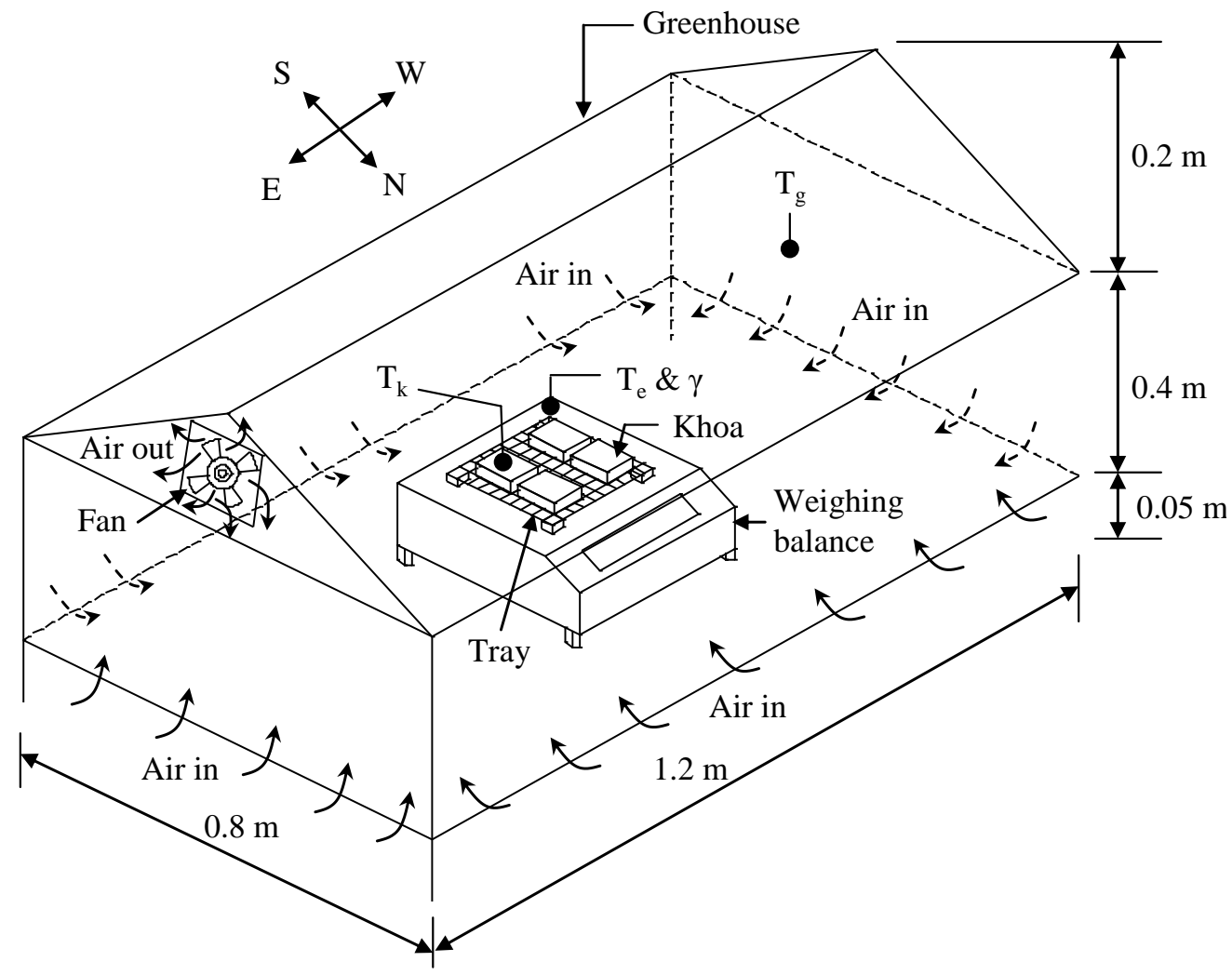

Figure 1. Schematic view of experimental unit.

\section{Sample Preparation, Experimental Observations and Procedure}

The fresh cow's milk was heated over an electric hot plate in a stainless steel open pan for making khoa. The heating was stopped when the desired consistency was obtained and the product was allowed to cool to room temperature. Then cuboid-shaped pieces of khoa of sizes $0.025 \times 0.02 \times 0.015 \mathrm{~m}^{3}, 0.0375 \times 0.03 \times 0.015 \mathrm{~m}^{3}$, and $0.075 \times 0.06 \times$ $0.015 \mathrm{~m}^{3}$ with a total quantity of $100 \mathrm{~g}$ were prepared with the help of wooden moulds. A fresh khoa sample of the same shape and mass was prepared for each run of the experiment by following the above procedure. The experiments were performed during the month of October 2012 at Guru Jambheshwar University of Science and Technology Hisar $\left(29^{\circ} 5^{\prime} 5^{\prime \prime} \mathrm{N} 75^{\circ} 45^{\prime} 55^{\prime \prime} \mathrm{E}\right)$ on a clear day. The initial mass of khoa samples for each experiment was kept the same, i.e., $100 \mathrm{~g}$. The khoa samples were kept in the wire mesh tray over the weighing balance inside the greenhouse structure. The moisture evaporated 
was calculated by taking the difference in mass between two consecutive observations. The hourly data for moisture removal, khoa temperature, relative humidity inside the greenhouse, and temperature just above the khoa surface during the experiments were recorded till no variation in mass of the khoa samples was observed.

\section{THEORETICAL CONSIDERATIONS}

\section{Thermal Modelling}

The rate of heat utilized to evaporate moisture is given as [6].

$$
\begin{gathered}
\dot{Q}_{e}=0.016 h_{c}\left[P\left(T_{k}\right)-\gamma P\left(T_{e}\right)\right] \\
h_{c}=\left(K_{v} / X\right) C(\operatorname{Re} \operatorname{Pr})^{n} \\
\dot{Q}_{e}=0.016 \times\left[\left(K_{v} / X\right)\right] C(\operatorname{Re} \operatorname{Pr})^{n}\left[P\left(T_{k}\right)-\gamma P\left(T_{e}\right)\right] \\
m_{e v}=0.016\left(K_{v} / X \lambda\right) C(\operatorname{Re} \operatorname{Pr})^{n}\left[P\left(T_{k}\right)-\gamma P\left(T_{e}\right)\right] A_{t} t \\
\left(m_{e v} / Z\right)=C(\operatorname{Re} \operatorname{Pr})^{n} \\
\ln \left[m_{e v} / Z\right]=\ln C+n \ln (\operatorname{Re} \operatorname{Pr})
\end{gathered}
$$

Equation (6) represents the straight line in the following form:

$$
y=m x+c
$$

Values of $m$ and $c$ in Eq. (7) are obtained by using the simple linear regression method by using the following formulae:

$$
\begin{gathered}
m=\left[N \sum x y-\sum x \sum y\right] /\left[N \sum x^{2}-\left(\sum x\right)^{2}\right] \\
C_{0}=\left[\sum x^{2} \sum y-\sum x \sum x y\right] /\left[N \sum x^{2}-\left(\sum x\right)^{2}\right]
\end{gathered}
$$

The constant ' $C$ ' and exponent ' $n$ ' were obtained from the above equations. The values of these constants were considered further to determine the convective heat transfer coefficient.

\section{Computation Technique}

The average khoa surface temperature $\left(T_{k}\right)$ and the temperature just above the khoa surface $\left(T_{e}\right)$ inside the greenhouse were calculated at hourly intervals for the corresponding moisture evaporation. The thermo-physical properties of humid air were evaluated and used to determine the values of the Reynolds number ( Re) and Prandtl number (Pr). The values of constant $C$ and exponent $n$ in the Nusselt number expression were determined by simple linear regression analysis and were used further to determine the values of the convective heat transfer coefficient $\left(h_{c}\right)$ from Eq. (2) at hourly increments of observation. The values of the convective heat transfer coefficients were used to evaluate the convective mass transfer coefficient from Eq. (10) as follows $[8]$ : 


$$
h_{m}=0.016 h_{c}\left[P\left(T_{p}\right)-\gamma P\left(T_{e}\right) /\left(T_{p}-T_{e}\right)\right]
$$

\section{Experimental Error}

The experimental error has been evaluated in terms of percent uncertainty (internal + external) for the rate of moisture evaporation by using the following equations:

$$
U_{I}=\sqrt{\left(\sigma_{1}^{2}+\sigma_{2}^{2}+\ldots \sigma_{N}^{2}\right)} / N_{o}
$$

$\%$ uncertainty $=\left(\mathrm{U}_{\mathrm{I}} /\right.$ mean of the total observations $) \times 100$

For external uncertainty, the least counts of all the instruments used in measuring the observation data were considered $[6,8]$.

\section{RESULTS AND DISCUSSION}

The experimental data obtained for khoa drying under the forced convection greenhouse mode for khoa samples having dimensions $0.025 \times 0.02 \times 0.015 \mathrm{~m}^{3}, 0.0375 \times 0.03 \times$ $0.015 \mathrm{~m}^{3}$, and $0.075 \times 0.06 \times 0.015 \mathrm{~m}^{3}$ are given in Table 1 .

\begin{tabular}{|c|c|c|c|c|}
\hline Time & $T_{k}\left({ }^{o} C\right)$ & $T_{e}\left({ }^{o} C\right)$ & $m_{e v} \times 10^{-3} \mathrm{~kg}$ & $\gamma(\%)$ \\
\hline \multicolumn{5}{|c|}{ First sample $\left(0.025 \times 0.02 \times 0.015 \mathrm{~m}^{3}\right)$ drying $($ October 13,2012$)$} \\
\hline $10-11 \mathrm{am}$ & 32.3 & 30.3 & 2.1 & 25.1 \\
\hline $11-12$ & 37.6 & 34.9 & 2.9 & 23.6 \\
\hline $12-1 \mathrm{pm}$ & 42.2 & 38.5 & 2.5 & 18.4 \\
\hline $1-2 \mathrm{pm}$ & 43.1 & 39.2 & 2.0 & 17.1 \\
\hline \multicolumn{5}{|c|}{ Second sample $\left(0.0375 \times 0.03 \times 0.015 \mathrm{~m}^{3}\right)$ drying $($ October 14,2012$)$} \\
\hline $10-11$ am & 31.5 & 29.7 & 2.0 & 29.7 \\
\hline $11-12$ & 36.8 & 34.3 & 2.2 & 24.3. \\
\hline $12-1 \mathrm{pm}$ & 41.9 & 38.4 & 1.9 & 20.1 \\
\hline $1-2 \mathrm{pm}$ & 42.4 & 38.6 & 1.1 & 19.0 \\
\hline \multicolumn{5}{|c|}{ Third sample $\left(0.075 \times 0.06 \times 0.015 \mathrm{~m}^{3}\right)$ drying $($ October 15,2012$)$} \\
\hline $10-11$ am & 31.8 & 29.9 & 1.6 & 28.8 \\
\hline $11-12$ & 37.9 & 35.1 & 2.1 & 23.2 \\
\hline $12-1 \mathrm{pm}$ & 42.8 & 39.1 & 1.7 & 21.3 \\
\hline $1-2 \mathrm{pm}$ & 43.2 & 39.2 & 1.1 & 20.5 \\
\hline
\end{tabular}

Table 1. Experimental data during forced convection greenhouse drying of khoa.

It can be seen from Table 1 that the moisture evaporation rate decreases with the increase in khoa sample size. The experimental data given in Table 1 were used to determine the values of the constant $C$ and exponent $n$ in the Nusselt expression by simple linear regression analysis. The values of these constants were considered further for determining the values of the convective heat transfer coefficient by Eq. (2). The values of the convective heat transfer coefficients were further used to evaluate the values of the convective mass transfer coefficients from Eq. (10). The values of 
experimental constants ( $C$ and $n$ ), the convective heat transfer coefficients $\left(h_{c}\right)$, and the convective mass transfer coefficients $\left(h_{m}\right)$ for drying all the khoa samples are summarized in Table 2. The range of Reynolds number and Prandtl number is also given. The product of the Reynolds and Prandtl numbers was observed to be less than $10^{5}$, i.e., $\operatorname{Re} \operatorname{Pr} \leq 10^{5}$. This indicates that the entire khoa drying for forced greenhouse modes falls within a laminar flow [9].

Table 2. Evaluated parameters and heat and mass transfer coefficients.

\begin{tabular}{|c|c|c|c|c|c|}
\hline$C$ & $n$ & $\operatorname{Re} \times 10^{3}$ & $\operatorname{Pr}$ & $\begin{array}{c}h_{c} \\
\left(\mathrm{~W} / \mathrm{m}^{2}{ }^{\circ} \mathrm{C}\right)\end{array}$ & $\begin{array}{c}h_{m} \\
\left(\mathrm{~W} / \mathrm{m}^{2}{ }^{\circ} \mathrm{C}\right)\end{array}$ \\
\hline \multicolumn{6}{|c|}{ First sample $\left(0.025 \times 0.02 \times 0.015 \mathrm{~m}^{3}\right)$ drying $($ October 13,2012$)$} \\
\hline 0.99 & 0.29 & $2.431-2.571$ & $0.696-0.697$ & $3.11-3.14$ & $92.49-94.58$ \\
\hline \multicolumn{6}{|c|}{ Second sample $\left(0.0375 \times 0.03 \times 0.015 \mathrm{~m}^{3}\right)$ drying $($ October 14,2012$)$} \\
\hline 0.99 & 0.26 & $2.439-2.581$ & $0.696-0.697$ & $2.48-2.51$ & $73.44-77.09$ \\
\hline \multicolumn{6}{|c|}{ Third sample $\left(0.075 \times 0.06 \times 0.015 \mathrm{~m}^{3}\right)$ drying $($ October 15,2012$)$} \\
\hline 0.99 & 0.24 & $2.430-2.578$ & $0.696-0.697$ & $2.13-2.17$ & $61.92-64.83$ \\
\hline
\end{tabular}

It is observed from Table 2 that the convective heat and mass transfer coefficients decrease with the increase in size of the khoa pieces. This is because of decrease in the removal of moisture content. It is also observed that both the convective heat and mass transfer coefficients do not vary much for each sample drying under the forced convection greenhouse mode. The values of convective heat and mass transfer coefficients are observed to be higher for the pieces with dimensions $0.025 \times 0.02 \times$ $0.015 \mathrm{~m}^{3}$. The hourly variations in the convective heat transfer coefficients and convective mass transfer coefficients for each sample of the given dimensions.

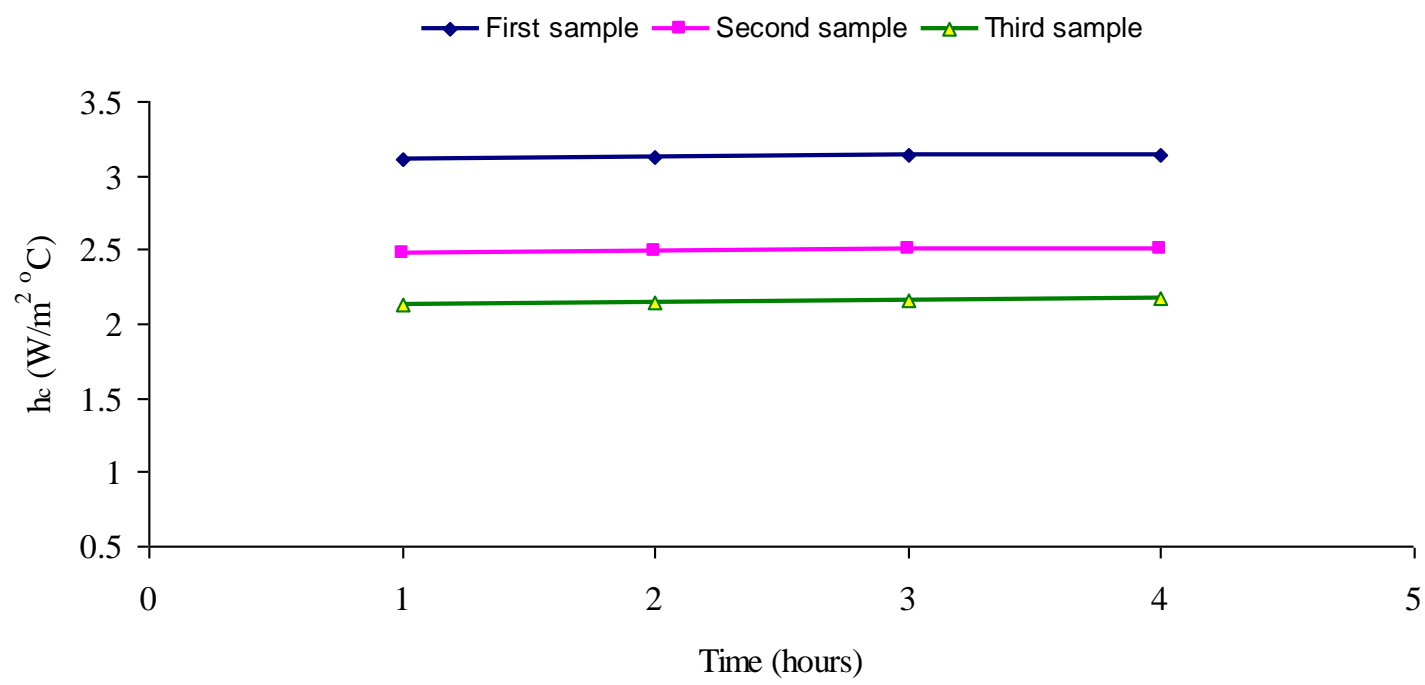

Figure 2. Convective heat transfer coefficients variations with time.

From Figures 2 and 3, it can also be seen that for each sample of khoa the convective heat and mass transfer coefficients do not change much with the progression of drying time. The average values of the convective heat transfer coefficients have also been calculated for each of the khoa sample sizes. The average values of convective 
heat transfer coefficients are found to be $3.13 \mathrm{~W} / \mathrm{m}^{2}{ }^{\circ} \mathrm{C}, 2.49 \mathrm{~W} / \mathrm{m}^{2}{ }^{\circ} \mathrm{C}$, and $2.15 \mathrm{~W} / \mathrm{m}^{2}$ ${ }^{\circ} \mathrm{C}$ for the khoa pieces of size $0.025 \times 0.02 \times 0.015 \mathrm{~m}^{3}, 0.0375 \times 0.03 \times 0.015 \mathrm{~m}^{3}$, and $0.075 \times 0.06 \times 0.015 \mathrm{~m}^{3}$ respectively. The average value of the convective heat transfer coefficients is observed to increase by $45.58 \%$ as the khoa sample size decreases from $0.075 \times 0.06 \times 0.015 \mathrm{~m}^{3}$ to $0.025 \times 0.02 \times 0.015 \mathrm{~m}^{3}$. This is due to an increase in the exposure of the khoa surface area to solar radiation, which causes an increased moisture removal rate. The average values of the convective heat transfer coefficients are plotted in Figure 4.

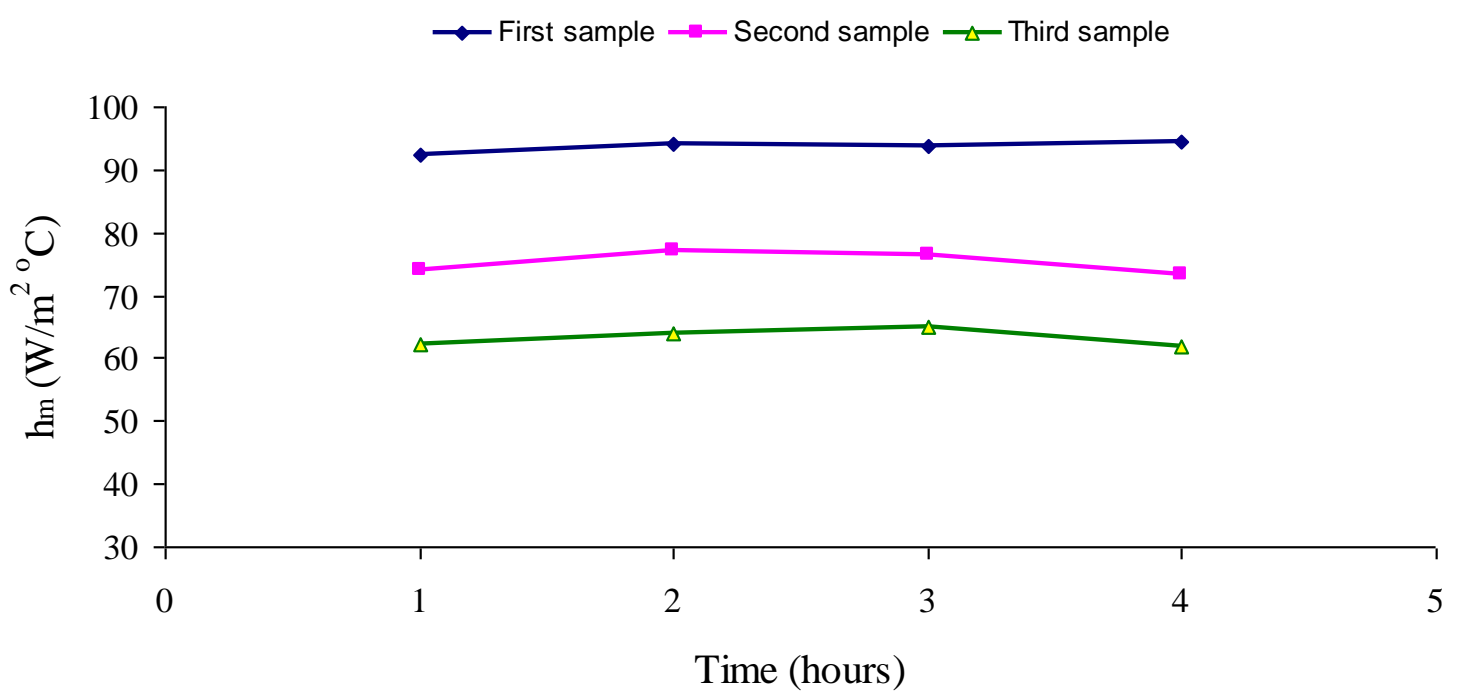

Figure 3. Convective mass transfer coefficients variations with time.

The results evaluated for the convective heat transfer coefficients under the forced convection greenhouse mode are also compared (Figure 4) with the results reported for natural convection greenhouse khoa drying mode under the same working conditions by Kumar [8]. The trends of the results obtained for convective heat transfer coefficients under the forced convection greenhouse mode are found to be similar to those of the natural convection greenhouse mode. The convective heat transfer coefficients under the forced convection greenhouse mode are found to be $23.71 \%$ to $35.22 \%$ higher than the natural convection greenhouse mode.

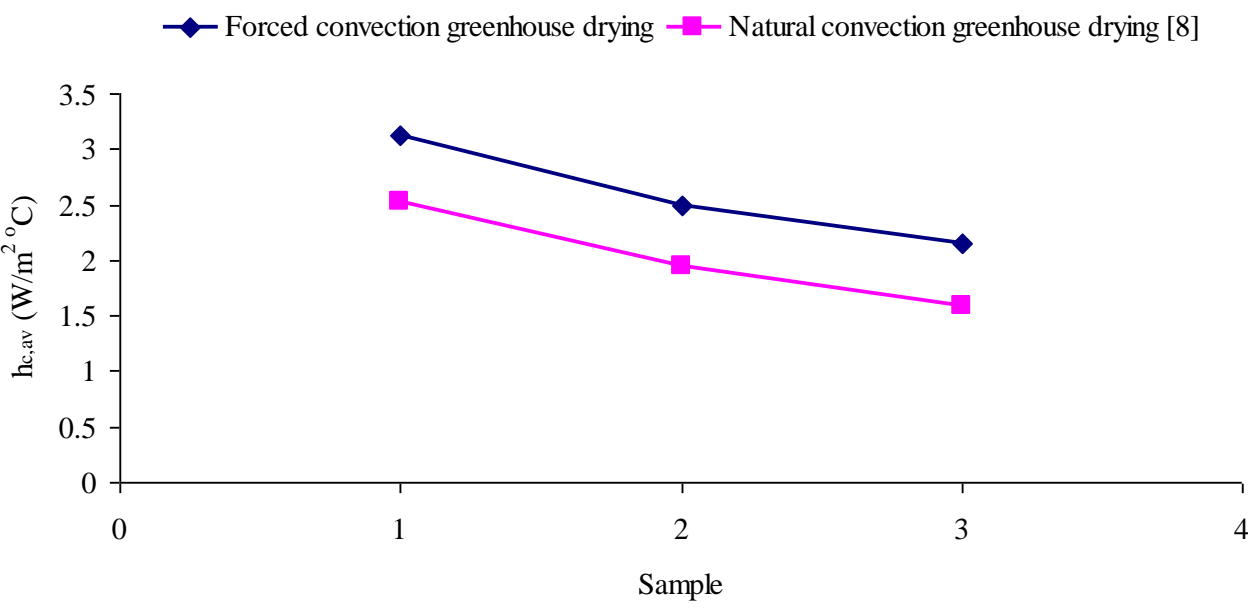

Figure 4. Average values of the convective heat transfer coefficients. 
The average values of the convective mass transfer coefficients are found to be 93.77 W/m $\mathrm{m}^{2}{ }^{\circ} \mathrm{C}, 75.28 \mathrm{~W} / \mathrm{m}^{2}{ }^{\circ} \mathrm{C}$, and $63.23 \mathrm{~W} / \mathrm{m}^{2}{ }^{\circ} \mathrm{C}$ for the khoa pieces of size $0.025 \times$ $0.02 \times 0.015 \mathrm{~m}^{3}, 0.0375 \times 0.03 \times 0.015 \mathrm{~m}^{3}$, and $0.075 \times 0.06 \times 0.015 \mathrm{~m}^{3}$ respectively. The average value of the convective mass transfer coefficients is observed to increase by $48.32 \%$ as the khoa sample size decreases from $0.075 \times 0.06 \times 0.015 \mathrm{~m}^{3}$ to $0.025 \times$ $0.02 \times 0.015 \mathrm{~m}^{3}$. This is because of the increase in convective heat transfer coefficients values with the decrease in size of the given khoa samples. The average values of the convective mass transfer coefficients for the given khoa samples are illustrated in Figure 5.

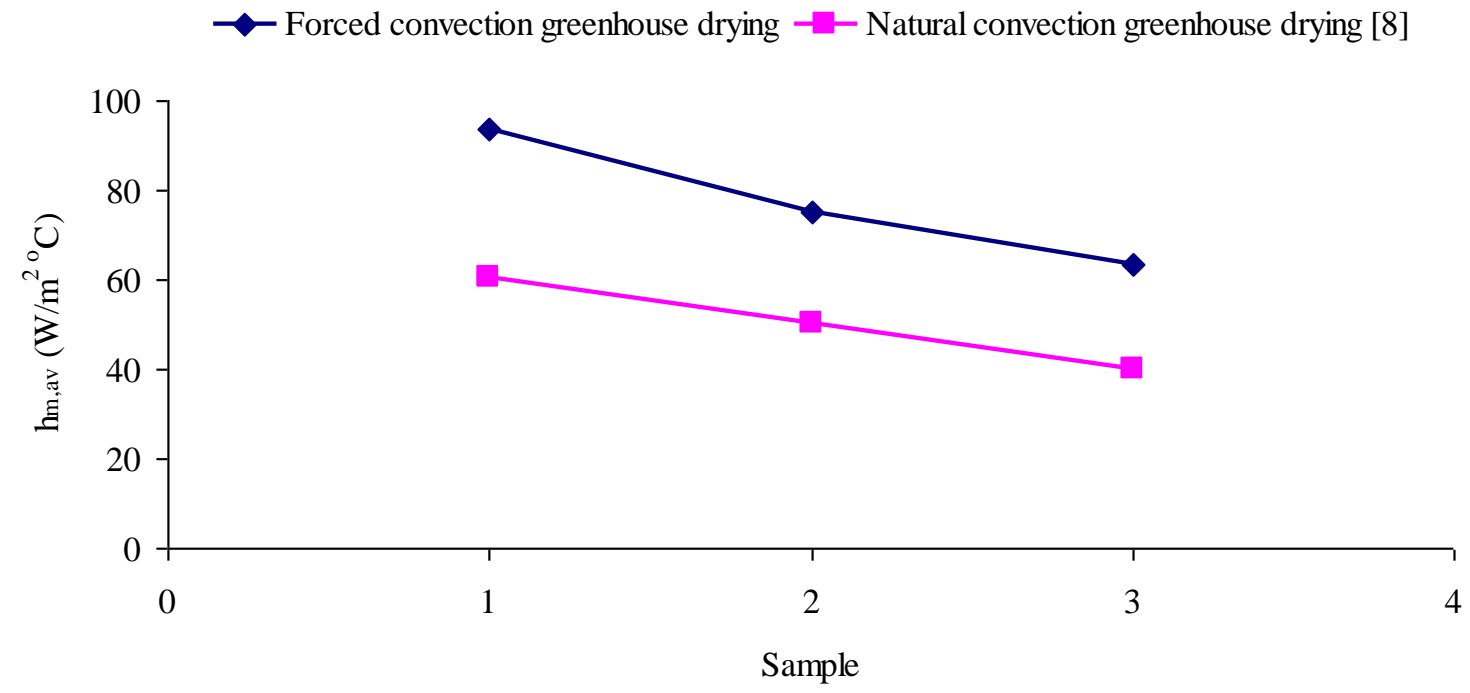

Figure 5. Average values of the convective mass transfer coefficients.

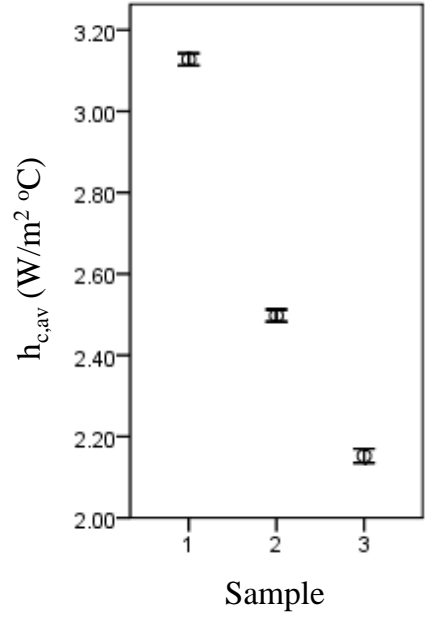

(a)

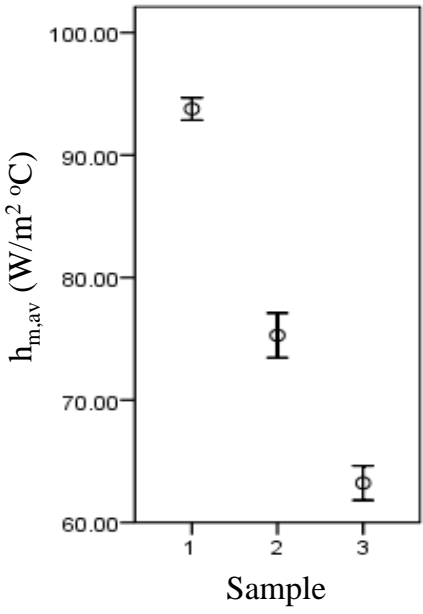

(b)

Figure 6. Error bars for the convective heat and mass transfer coefficients.

The values of the convective mass transfer coefficients for khoa drying under the forced convection greenhouse mode are also compared (Figure 5) with the results reported for the natural convection greenhouse khoa drying mode under the same working conditions by Kumar [8]. The trends of the results for the convective mass transfer coefficients under the forced convection greenhouse mode are found to be similar to those of the natural convection greenhouse mode. The convective mass transfer coefficients under the forced convection greenhouse mode are found to be 
$49.81 \%$ to $58.25 \%$ higher than the natural convection greenhouse mode. The experimental error in terms of percent uncertainty (internal + external) is observed to vary in the range of $14.99 \%$ to $23.24 \%$. The different values of the convective heat and mass transfer coefficients were found to be within the given range. In order to show the variability of the convective heat and mass transfer coefficients from their error-free values (true value), error bars of $95 \%$ confidence interval have been plotted with the help of SPSS software (version 16.0). The error bars for the convective heat and mass transfer coefficients are shown in Figure 6.

\section{CONCLUSIONS}

This research work presents the effect of size on the convective heat and mass transfer coefficients for khoa (a heat-desiccated milk product) drying in a given size of roof type even span greenhouse $\left(1.2 \times 0.8 \mathrm{~m}^{2}\right)$ under forced convection mode. Khoa pieces of dimensions $0.025 \times 0.02 \times 0.015 \mathrm{~m}^{3}, 0.0375 \times 0.03 \times 0.015 \mathrm{~m}^{3}$, and $0.075 \times 0.06 \times$ $0.015 \mathrm{~m}^{3}$ making a total quantity of $100 \mathrm{~g}$ are dried. The convective heat and mass transfer coefficients are observed to decrease with the increase in size of the khoa pieces. This is due to a decrease in the removal of moisture content because of less exposure of the khoa surface to the radiation. The convective heat and mass transfer coefficients are greater for the pieces of dimensions $0.025 \times 0.02 \times 0.015 \mathrm{~m}^{3}$. The average values of the convective heat and mass transfer coefficients are found to increase from $2.15 \mathrm{~W} / \mathrm{m}^{2}{ }^{\circ} \mathrm{C}$ to $3.13 \mathrm{~W} / \mathrm{m}^{2}{ }^{\circ} \mathrm{C}$ and $63.23 \mathrm{~W} / \mathrm{m}^{2}{ }^{\circ} \mathrm{C}$ to $94.95 \mathrm{~W} / \mathrm{m}^{2}{ }^{\circ} \mathrm{C}$ respectively as the size of khoa pieces decreases from $0.075 \times 0.06 \times 0.015 \mathrm{~m}^{3}$ to 0.025 $\times 0.02 \times 0.015 \mathrm{~m}^{3}$. Thus, from the present research work, it is inferred that the size of khoa pieces plays a significant role in its drying. This research work would be useful in the design of an efficient greenhouse dryer for khoa drying to its optimum storage moisture level.

\section{ACKNOWLEDGEMENTS}

The author is obliged to Guru Jambheshwar University of Science and Technology for providing laboratory facilities.

\section{REFERENCES}

[1] Kumar M, Prakash O, Kasana, KS, Dabur RS. Technology advancement in khoa making. Indian Dairyman. 2010;62:64-70.

[2] Kumar M. Up-gradation of Khoa Production and Preservation Technologies. SAMRIDDHI- A Journal of Physical Science Engineering and Technology. 2013;4:37-46.

[3] Condorí M, Saravia L. The performance of forced convection greenhouse driers. Renewable Energy. 1998;13:453-69.

[4] Condorí M, Echazú R, Saravia L. Solar drying of sweet pepper and garlic using the tunnel greenhouse drier. Renewable Energy. 2001;22:447-60.

[5] Tiwari GN, Kumar S, Prakash O. Evaluation of convective mass transfer coefficient during drying of jaggery. Journal of Food Engineering. 2004;63:21927. 
[6] Kumar A, Tiwari GN. Effect of shape and size on convective mass transfer coefficient during greenhouse drying (GHD) of Jaggery. Journal of Food Engineering. 2006;73:121-34.

[7] Kumar M, Khatak P, Sahdev RK, Prakash O. The effect of open sun and indoor forced convection on heat transfer coefficients for the drying of papad. Journal of Energy in Southern Africa. 2011;22:40-6.

[8] Kumar M. Effect of size on the convective heat and mass transfer coefficients during natural convection greenhouse drying of khoa-heat desiccated milk product. International Journal of Renewable Energy \& Biofuels 2014;2014:1-11.

[9] Kumar M, Kasana KS, Kumar S, Prakash O. Experimental investigation on convective heat transfer coefficient for khoa drying. International Journal of Current Research. 2011;3:88-93.

\section{NOMENCLATURES}

$\begin{array}{ll}A_{t} & \text { Area of tray, } \mathrm{m}^{2} \\ C & \text { Experimental constant } \\ C_{v} & \text { Specific heat of humid air, } \mathrm{J} / \mathrm{kg}{ }^{\circ} \mathrm{C} \\ g & \text { Acceleration due to gravity, } \mathrm{m} / \mathrm{s}^{2} \\ h_{c} & \text { Convective heat transfer coefficient, } \mathrm{W} / \mathrm{m}^{2}{ }^{\circ} \mathrm{C} \\ h_{c, a v} & \text { Average convective heat transfer coefficient, } \mathrm{W} / \mathrm{m}^{2}{ }^{\circ} \mathrm{C} \\ h_{m} & \text { Convective mass transfer coefficient, } \mathrm{W} / \mathrm{m}^{2}{ }^{\circ} \mathrm{C} \\ h_{m, a v} & \text { Average convective mass transfer coefficient, } \mathrm{W} / \mathrm{m}^{2}{ }^{\circ} \mathrm{C} \\ K_{v} & \text { Thermal conductivity of humid air, W/m }{ }^{\circ} \mathrm{C} \\ m_{e v} & \text { Mass evaporated, kg } \\ n & \text { Experimental constant } \\ N & \text { Number of observations in each set of tables } \\ N_{o} & \text { Number of sets } \\ N u & \text { Nusselt number }=\left(h_{c} X / K_{v}\right) \\ \operatorname{Pr} & \text { Prandtl number }=\left(\mu_{v} C_{v} / K_{v}\right) \\ P(T) & \text { Partial vapour pressure at temperature T, N/m }{ }^{2} \\ Q_{e} & \text { Rate of heat utilized to evaporate moisture, } \mathrm{J} / \mathrm{m}^{2} \mathrm{~s} \\ \operatorname{Re} & \text { Reynolds number }=\left(\rho_{v} V X / \mu_{v}\right) \\ T_{k} & \text { Temperature of khoa surface, }{ }^{\circ} \mathrm{C} \\ T_{e} & \text { Temperature just above the khoa surface, }{ }^{\circ} \mathrm{C} \\ t & \text { Time, } \mathrm{s} \\ \Delta T & \text { Effective temperature difference, }{ }^{\circ} \mathrm{C} \\ V & \text { Air velocity inside greenhouse, } \mathrm{m} / \mathrm{s} \\ X & \text { Characteristic dimension, } \mathrm{m}\end{array}$

Greek symbols

$\beta \quad$ Coefficient of volumetric expansion $\left(\mathrm{K}^{-1}\right)$

$\gamma \quad$ Relative humidity (\%) 
$\lambda \quad$ Latent heat of vaporization, $\mathrm{J} / \mathrm{kg}$

$\mu_{v} \quad$ Dynamic viscosity of humid air, $\mathrm{N} \mathrm{s} / \mathrm{m}^{2}$

$\rho_{v} \quad$ Density of humid air, $\mathrm{kg} / \mathrm{m}^{3}$

\section{APPENDIX I}

The thermo-physical properties of humid air were evaluated for the mean temperature $T_{i}=\left[\left(T_{k}+T_{e}\right) / 2\right]$ by using the following equations $[5,8]$ :

$$
\begin{gathered}
C_{v}=999.2+0.1434 T_{i}+1.101 \times 10^{-4} T_{i}^{2}-6.7581 \times 10^{-8} T_{i}^{3} \\
K_{v}=0.0244+0.7673 \times 10^{-4} T_{i} \\
\rho_{v}=353.44 /\left(T_{i}+273.15\right) \\
\mu_{v}=1.718 \times 10^{-5}+4.620 \times 10^{-8} T_{i} \\
P(T)=\exp \left[25.317-5144 /\left(T_{i}+273.15\right)\right]
\end{gathered}
$$

